\title{
Six Sigma Approach to Enhance Concurrency of the Procurement Process for Raw Materials
}

\author{
Atanas Kochov*, Aleksandar Argilovski
}

\begin{abstract}
This paper presents the improvement of the procurement process for raw materials in a real manufacturing company supported by the Lean Sig Sigma as structured approach to deliver the improvement. The manufacturing company that is a subject of this paper have received a significant amount of complains regarding the internal purchase orders approval process and the overall procurement process of the company from both internal employees and external vendors and contractors. Considering that the company is procuring the raw goods from selected vendors, therefore the entire manufacturing plan depends on these materials, the company decided to improve this process trough Lean Six Sigma. The Lean Six Sigma approach was selected in order to obtain the improvement in a short time, based on indicators that were previously analyzed and prioritized. The paper focuses on simplifying of the process trough decreasing the number of mandatory steps.
\end{abstract}

Keywords: concurrent engineering; Lean; manufacturing; procurement; raw materials; Six Sigma

\section{INTRODUCTION}

The purchasing of the raw materials is one of the key features of the production planning and control process. Although sometimes this process is viewed as administrative and repetitive, it should be strategic and based on the current needs for purchasing of the companies.
It is one of the most important factors that affects the shortening of the production plan and therefore enhancement of the competitiveness of the entire company on the market. Once this process is optimized and thought through, it could also generate a lot of savings for the companies as well as improve the relationships with the external contractors, vendors, and suppliers.

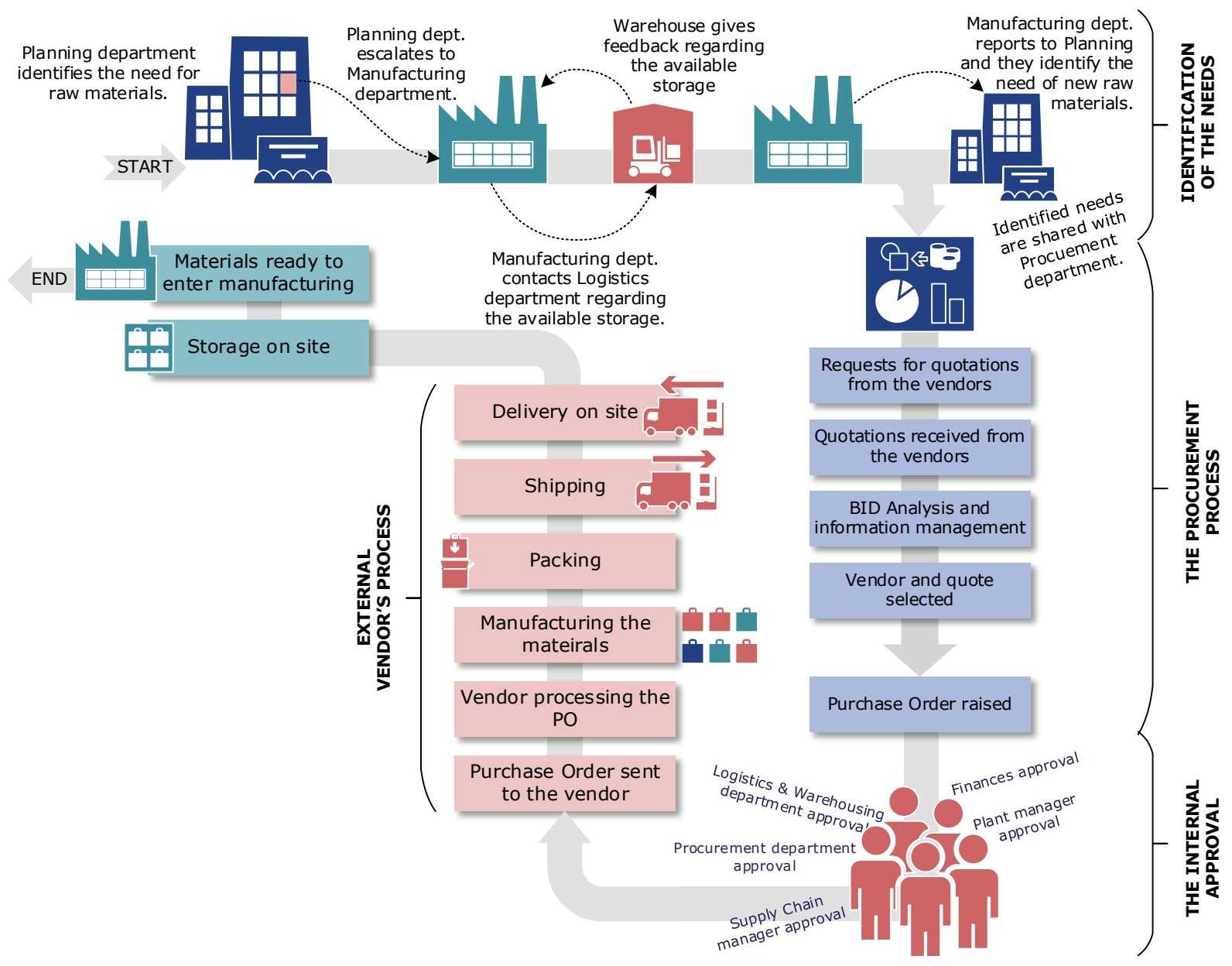

Figure 1 Map of the current process 
Six Sigma puts the customers (or suppliers) first and uses the facts and data to drive better solutions and improve processes [1]. Six Sigma efforts target three main areas: improving customer (or other types of associates) satisfaction, reducing process cycle time and reducing defects.

The case given in this paper is focused on improving a process to both reduce the process cycle time but also improve the relationships with one of the most important associates of the production companies - the suppliers of raw materials. Besides having the supplies responsible for the design, quality or performance of the materials, the production companies must work closely and transparently with the main suppliers. Considering that the manufacturing companies are highly dependent on the suppliers, actions such as these small improvements in the communication or easing the procedures for collaboration, can prevent a factory collapse, in more senses, starting from not producing enough, to building inventory or even cause environmental issues due to inadequate products or supplied materials.

PO (or purchase order) could be defined as "request for purchase", in fact is an official confirmation from the buyer that they accept the quotation issued from the seller and they are willing to purchase the goods or services offered by the seller. A PO is the simplest type of fixed price contract [2]. The shortening of the administrative or technical process of issuing a $\mathrm{PO}$, will help both the production company and the seller's company. Besides the enhancement of the production plan and the reduction of the responsibilities for the employees, the improvement of this process will also improve the communication between both sides which leads to opportunities for both sides (the buyer and the seller) such as further business collaborations, contracts, discounts etc. The benefit of this improvement could be monetarized through the reduction of manpower and shortening of the production plan.

The problem that is covered in this paper is taken from real manufacturing company (Company A). The extended process of identification of the needs for purchasing and the purchasing itself in this company is illustrated in Fig. 1. The suppliers of this company are constantly complaining about the significantly long time for receiving of the official order (PO) from the manufacturing company counted from the moment when they issue their financial quotation. The current lead time for defining the needs and releasing PO for raw materials in the Company $\mathrm{A}$ is approximately 51 working hours.

The project will be led according to the DMAIC framework (define, measure, analyse, improve and control) since this improvement is being implemented on already existing process [3].

The project team is consisted of:

- $\quad$ Project sponsor (1 member) - business representative (in this case the Plant manager) and project initiator,

- Six Sigma Black Belt (1 member) - to translate business goals into Six Sigma deliverables, define Six sigma strategy and mentor other involved sides.

- $\quad$ Six Sigma Green Belts (2 members) - for project tools execution to deliver results.
Due to the type of the process (cross-departmental) several other employees from different departments were contacted to gather the needed data (especially in the Measure phase).

\section{DEFINE}

To define the problem, the team will issue problem and goal statement based on the requirements of the project sponsor (the Plant Manager of Company A) as well as the voice of the stakeholders that are directly involved in this process. Other project management aspects such as resources, time and cost are also finalized in this phase, but this will not be showcased within this paper in details.

The time required to implement this improvement is estimated to be three months with minimum costs needed for the improvement of the purchasing system.

\subsection{User Requirements}

This process has several users such as the different suppliers of raw materials and all the internal departments that are included in this process such as Planning, Purchasing, Manufacturing, Transport \& Logistics, Finances, Supply Chain and finally, the sponsor of the project - the Plant Manager of Company A.

To gather user requirements, Six Sigma offers tool that is as simple as "Voice of the customer (VOC)". "Customers" of this process are all above mentioned sides that are part of the process in any way. Fig. 3 is showcasing the full VOC analysis for the project.

\subsection{Problem and Goal Statement}

The problem and the goal statements are one of the main starting point of the Six Sigma project. The statements should be based on a brainstorming session within the team - they should be short and perfectly clear to the team. Fig. 2 is showing the "Problem Statement" and the "Goal Statement" for this project.

\begin{tabular}{|c|c|}
\hline PROBLEM STATEMENT & GOAL STATEMENT \\
\hline $\begin{array}{l}\text { 66 The process of } \\
\text { procurement of raw } \\
\text { materials in the company } \\
\text { needed as base for the } \\
\text { manicuring process is too } \\
\text { long and complicated } \\
\text { which results with delays } \\
\text { of the manufacturing and } \\
\text { unsatisfied clients and } \\
\text { suppliers. }\end{array}$ & $\begin{array}{l}\text { 66 The goal of the project is } \\
\text { to shorten the time } \\
\text { needed for the needs } \\
\text { identification and } \\
\text { procurement of the raw } \\
\text { materials, reduce the } \\
\text { steps and approvers and } \\
\text { increase the concurrency } \\
\text { of the process. }\end{array}$ \\
\hline
\end{tabular}

Further explanations of these statements could be done in a separate document, if needed. 


\section{CUSTOMER}

"We wait for several days to get the PO after issuing the quote"

"Do not ignore our follow-up e-mails"

"Asking/giving quotes for the same time
over and over is counterproductive - we are
serious in doing business with you"

"Orders usually don't reflect the number of the exact number of quoted parts"

"You usually ask us to ship/prepare the parts before you officially place the PO"

"The relationship with our suppliers is not very good because we are very late with the POs"

"We received strikes from our clients that didn't received our products on time"

“We don't have enough space to store all materials"

"We noticed that the discounts given by the
suppliers are decreased by $40 \%$ in the past
year"

"The project plan is changing frequently to reflect the available raw materials"

"Approving the POs is not my primary job, so
I am aware that I am late with the
approvals"

"There are too many levels of approval, we have to follow-up them all the time"
WHY ARE THEY SAYING IT?

Suppliers need the decisions as soon as

possible because they plan all quoted

materials same as the ordered ones.

The suppliers need information in order to

plan their capacities. They could take this as bad collaboration from the Company A.

The suppliers spend a lot of time to prepare the quotes for the same quantities and materials over and over.

Company A sometimes takes liberty to set more parts in the orders than the quoted number. This is not good for supplier's plan.

The suppliers can't send their parts before the business is confirmed with a PO.

Procurement employees think that the process of internal PO processing is very slow.

Not having enough raw materials to produce the parts on time resulted with losing business with the clients of Company $A$. Logistics (Warehouse) department is struggling with the quantities of raw materials sometimes.

Procurement team is not able to reach their discounts goals from the suppliers because they have been unreliable in the past.

Planning department should modify the plan according to available raw materials - no matter if these parts are not critical.

The Plant Manager is aware that they are late with the approval of the POs.

Procurement is struggling to make all managers/supervisors to approve on time.
WHAT DO THEY NEED?

They need standard process with defined time

of waiting to get PO after the Company's decision.

They need frequent feedback even if this feedback is negative (not accepting the quote).

The supplier means that they want to set mutually standardized process for procurement of these standard materials

Previously defined specification regarding the quantities that will satisfy the production and the storage requirements of Company $A$. Understanding that the $\mathrm{PO}$ is crucial confirmation for them to even start preparing the materials for dispatch.

Reduction of the administrative work.

Process that will ensure that all raw materials are in Company A just in time.

The inventory of raw materials should be as optimized as possible because inventory generates waste.

Fast and transparent process is needed.

Just-in-Time delivery of all raw materials in order not to produce uncritical parts just to keep the equipment running. Introduce different type of control and exclude the Plant Manager and other unnecessary approvers from the process.

Exclude all unnecessary approvers from the process and find a way to have them responsible earlier in the process.

Figure 3 Voice of the customer

As stated in Fig. 2, the main goal is to transform this process into more concurrent (parallel) process and therefore shorten the time needed for processing the orders. Besides shortening and clarifying the procurement process, this will shorten the production plan as well as reduce the risks of deficiency of raw materials for the production process. To clarify this, the project team expanded the goal statement and brainstormed several additional benefits/points how to transform the current traditional procurement into contemporary procurement that will be driven by the Lean philosophy and concurrent engineering fundamentals.

As seen on Fig 4., thanks to the LEAN and concurrent engineering principles, some of the usual steps of the procurement process will be transformed which means smaller order sizes, agility, frequent control, performing more steps parallelly, standardization of the steps and implementation of Just-In-Time (JIT) methodology. These directions will be the focus of the team during the Improve phase, but also will help to define the Key Performance Indicators that will measure the success of this improvement after the implementation.
TRADITIONAL PROCUREMENT

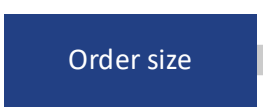

Big size, based on previous experiences

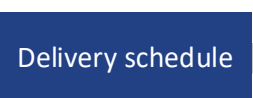

Rare deliveries, big sizes and higher costs

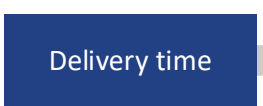

Long and relaxed, rare follow-ups

Quality of the

received parts

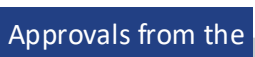

management

Requests for quotations

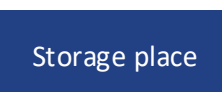

Figure 4 Transformation of

Responsibility of the buyer

Sequential, no previous introduction

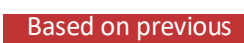

experiences, repetative

No care for the needed storage
LEAN (COCURRENT) PROCUREMENT

Smaller sizes, based on the current needs

Frequent deliveries, small sizes and costs

Short and agile, highly controlled

Responsibility of the seller

Order only if storage is available of traditional procurement to LEAN (concurrent) procurement process 


\subsection{SIPOC}

Considering that the Define phase is laying-out the general characteristics of the problem/process, the SIPOC gives high-level management that simplifies and separates the process variables in five groups: Suppliers, Inputs, Process, Outputs and Customers. The SIPOC analysis for the discussed problem is shown in Fig. 5.

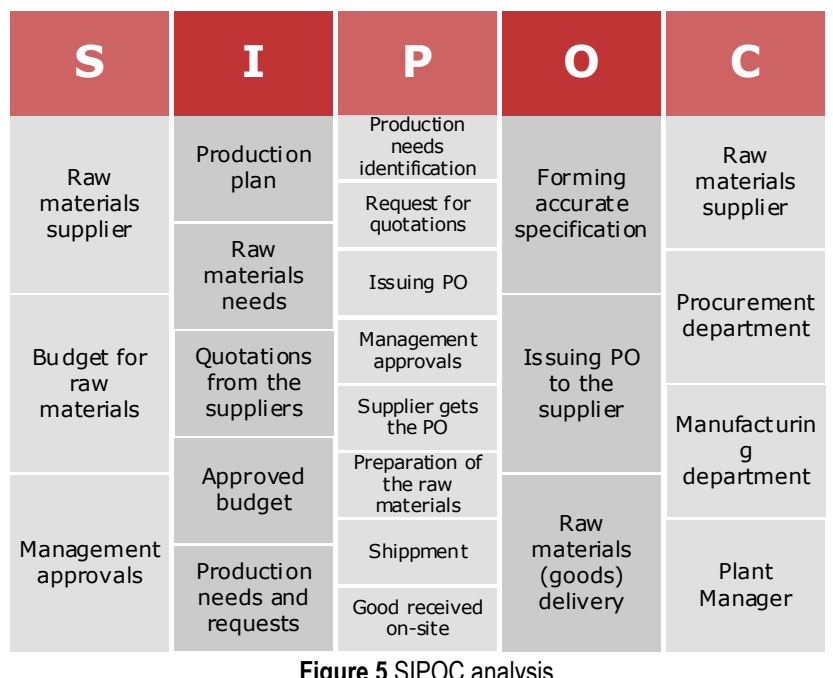

\section{MEASURE}

The purpose of this step is to thoroughly understand the current state of the process and collect reliable data on the process time, quality and costs and use that data to identify possible bottleneck, to set clear and measurable goals and have real figures for comparation and confirmation of the improvement at the end of the project [1].

\subsection{Mapping of the Current Process}

The current process was observed several times so that the team be able to map it in a simple flowchart. Fig. 1 is giving more realistic view on this process but when it comes to using the Six Sigma tools in the right way, a flowchart should be created to have clear overview of the steps. This will also help to set the KPIs and identify the value-added and non-value-added steps in the process.

The flowchart for the process is shown in Fig. 6. On a first look, it is obvious that this process is not predictable and straight forward. It includes few decisions that could end-up with at least two outputs, sub-steps that are time consuming, manual steps etc. This process could be easily separated in few different processes such as (a) the identifying of the needs, (b) the administrative procurement process (c) the supplier's process. For this process, this is unwanted due to the connection between all these sub-processes. This process is specific, and all of these steps need to be integrated and the participants to be as involved in each one of them as much as possible and as early as possible.

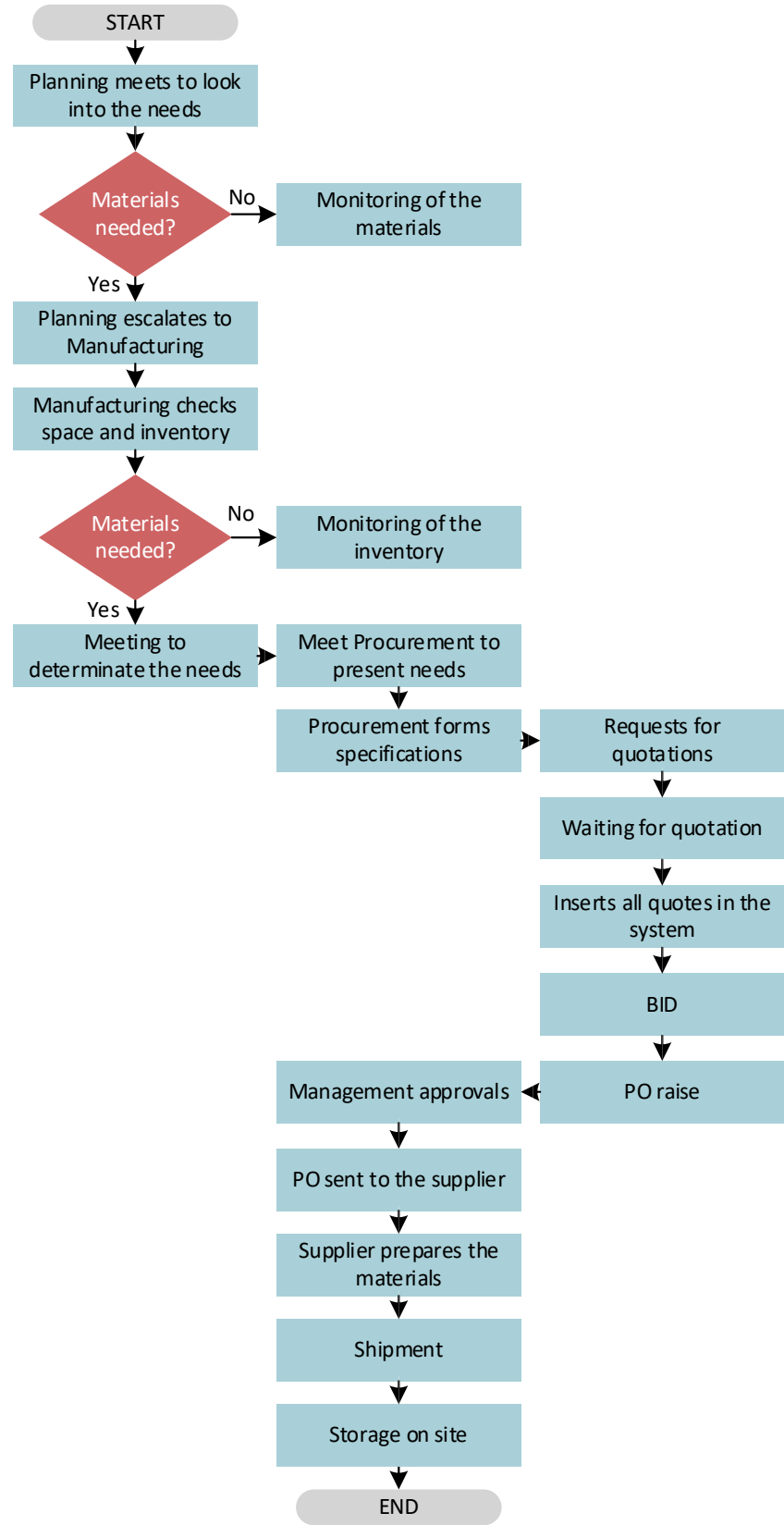

Figure 6 Map of the current process

It is easy to observe that the process is sequential - there are many "walls" (Fig. 7) [4] between the departments that are driving this process and these walls are the main sources of miscommunications, delays and variations of this process.

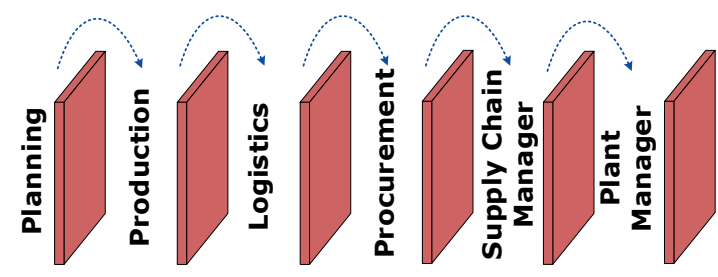

Figure 7 "Walls" between the stakeholders of the process 


\subsection{Key Performance Indicators}

Tab. 1 is showing the generated and measured KPIs of the current process. The KPIs are generated based on the goal of the project because these KPI values will be compared with the same values measured at the end of the project.

Table 1 Key performance indicators summary
\begin{tabular}{|l|c|c|}
\hline \multicolumn{1}{|c|}{ Indicator } & Unit & Value \\
\hline hours needed for vendors to receive PO & working hours & 16,5 \\
\hline mistakes in the Purchase Orders & mistake/month & 9 \\
\hline discounts from the suppliers monthly & $€$ & $4 \mathrm{k}$ \\
\hline delays of parts delivery due delay of the PO & working hours & 16 \\
\hline response time to vendor's questions & $\mathrm{h}$ & 8 \\
\hline number of steps in the procurement process & steps & 22 \\
\hline number of approvers & person & 7 to 10 \\
\hline length of the full process & $\mathrm{h}$ & 116 \\
\hline
\end{tabular}

\section{ANALYSE}

The Analyse phase for this project will focus on two main things: the investigation of the root cause and identification of the obsolete steps in the current process the steps that do not add any value for the clients/suppliers or the Company A itself. The data is gathered mostly by observation of the current process and interviewing.

\subsection{Why}

The 5 Why analysis [5] is an easy and creative way to identify the root cause of the problem and give one more direction to the team for designing better solution.

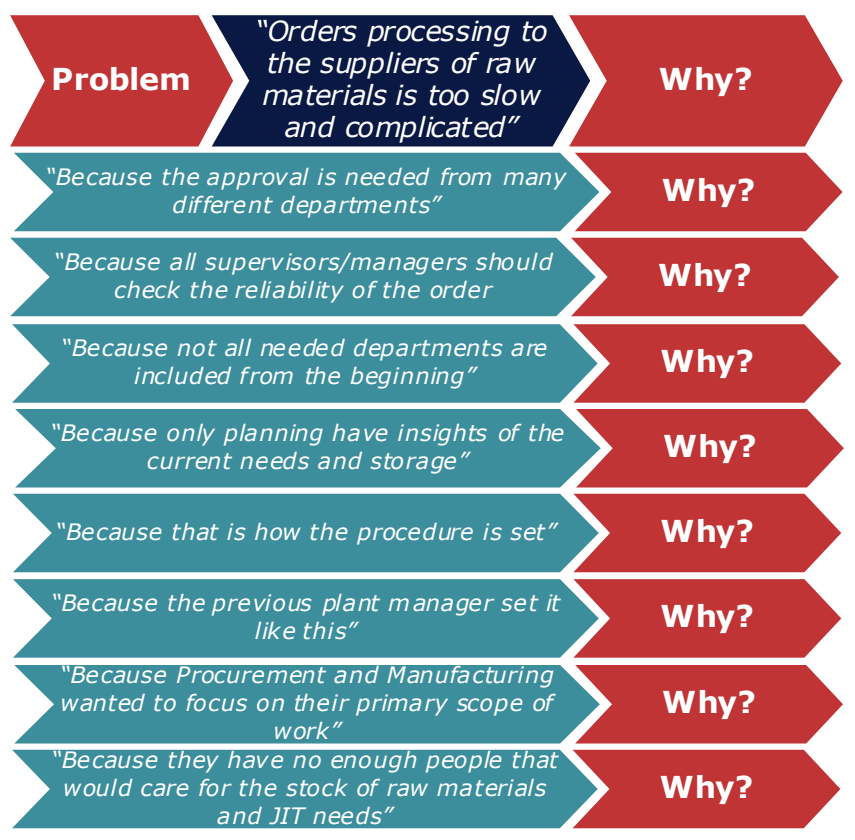

Figure $85 \mathrm{WHY}$ analysis

The analysis shown on Fig. 8 states gives a perspective what could be the potential root causes for this problem, finally concluding that the careless approach to stock and Just-in-Time needs of raw materials is causing the problems.

\subsection{Value-Added Analysis}

To identify which steps are obsolete in this process, Value-added analysis [1] will be performed. This analysis consists of three different types of activities that are assigned to each step of the process [6]. These activities are defined as such:

- value-added activities - activity/step which adds any value that a customer is willing to pay for to the manufacturing company,

- non-value-added steps - opposite to the value-added steps, these activities do not add any value to the finished product, these activities consume time, space and resources but they do not contribute to satisfy the customer's needs at the end, these steps also generate waste (Fig. 9) [6],

- necessary steps - these activities/steps are also consuming time, space and resources and do not contribute to produce what the customer wants, but these steps are needed or mandatory in the process.

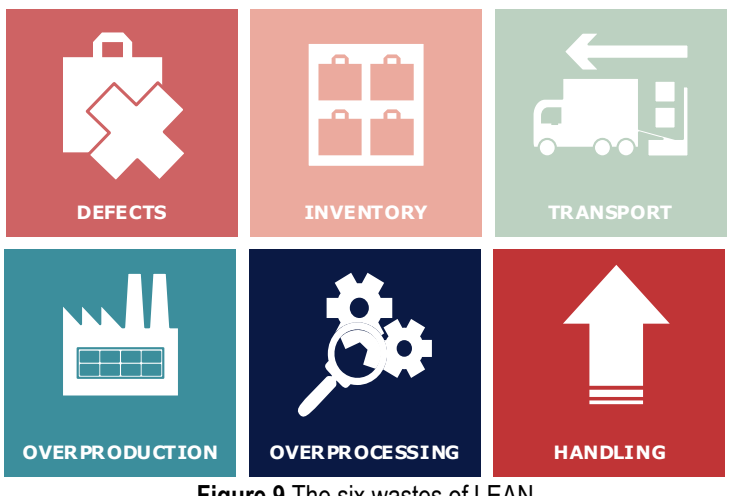

Figure 9 The six wastes of LEAN

The goal of the value-added analysis is to classify all steps of the process as steps that add value, steps that do not add value and necessary steps [1]. There should always be steps that add value and these steps should stay in the process. The ones that do not add value should be immediately eliminated, and the ones that are necessary, even though they don't add any value, they cannot be eliminated, therefore these steps should be optimized or reduced to minimum.

For this analysis, a flowchart is needed (could be used the one in Fig. 6) and a table laying out all the steps. We will also get back to the Measure phase outcomes and use the results in the table to find out which steps are doing the most "damage" to the process.

Since the team is mostly focused on shortening the time of this process, the lead time of all steps should be measured and set in the table (in the Lead time column, all values are in hours). After that, all steps are labelled according to the fact if they add value (VA column) to the process/products or the company, they do not add value (NVA column) or they are simply necessary ( $\mathrm{N}$ column). After this segregation, the "non-value-added" steps are being eliminated, and then the team decides for the further improvement or rearrangement of the value-added and the necessary steps (Action column will state the future of the given step of the process). Tab. 2 
is summarizing the Value-added analysis for the problem reviewed in this study.

\begin{tabular}{|c|c|c|c|c|c|}
\hline \multirow{2}{*}{ Step } & \multirow{2}{*}{$\begin{array}{l}\text { Lead } \\
\text { time }\end{array}$} & \multicolumn{3}{|c|}{ Type of Value-added } & \multirow{2}{*}{ Action } \\
\hline & & VA & NVA & $\mathrm{N}$ & \\
\hline $\begin{array}{l}\text { Meeting for the needs of } \\
\text { raw materials }\end{array}$ & 2 & & & 2 & Improve \\
\hline $\begin{array}{l}\text { Escalation to } \\
\text { Manufacturing }\end{array}$ & 0,5 & & 0,5 & & Eliminate \\
\hline Checks in Warehouse & 1 & & 1 & & Eliminate \\
\hline $\begin{array}{l}\text { Feedback from } \\
\text { Warehouse }\end{array}$ & 0,5 & & 0,5 & & Eliminate \\
\hline $\begin{array}{l}\text { Manufacturing \& } \\
\text { Planning meet to } \\
\text { determinate needs }\end{array}$ & 1,5 & & 1,5 & & Eliminate \\
\hline $\begin{array}{l}\text { Meeting with } \\
\text { Procurement to present } \\
\text { needs }\end{array}$ & 0,5 & & 0,5 & & Eliminate \\
\hline $\begin{array}{l}\text { Procurement forms } \\
\text { specification }\end{array}$ & 2 & 2 & & & Keep \\
\hline Request for quotation & 2 & 2 & & & Keep \\
\hline Waiting for quotations & 24 & & & 24 & Keep \\
\hline $\begin{array}{l}\text { Insert all quotes in the } \\
\text { system }\end{array}$ & 1 & & & 1 & Improve \\
\hline BID analysis & 1 & & & 1 & Improve \\
\hline $\begin{array}{l}\text { Vendor selection and } \\
\text { quote selection }\end{array}$ & 1 & & & 1 & Improve \\
\hline PO Raise & 0,1 & & & 0,5 & Improve \\
\hline Manufacturing approval & 1 & & 1 & & Eliminate \\
\hline Planning approval & 1 & & 1 & & Eliminate \\
\hline Logistics Approval & 1 & & 1 & & Eliminate \\
\hline $\begin{array}{l}\text { Finances checks } \\
\text { available budget }\end{array}$ & 3 & & 3 & & Eliminate \\
\hline Finances approval & 1 & & & 1 & Keep \\
\hline Procurement approval & 1 & & 1 & & Eliminate \\
\hline $\begin{array}{l}\text { Supply chain manager } \\
\text { approval }\end{array}$ & 2 & & 2 & & Keep \\
\hline Plant manager approval & 3 & & 3 & & Eliminate \\
\hline PO sent to the vendor & 0,5 & & & 0,5 & Keep \\
\hline Vendor process the $\mathrm{PO}$ & 1 & & & 1 & Keep \\
\hline $\begin{array}{l}\text { Manufacturing of the } \\
\text { materials }\end{array}$ & 40 & 40 & & & Keep \\
\hline Packing & 2 & 2 & & & Keep \\
\hline Shipping & 16 & & & 16 & Keep \\
\hline Delivery on site & 2 & & & 2 & Keep \\
\hline Storage on site & 3 & & & 3 & Improve \\
\hline $\begin{array}{l}\text { Materials enter } \\
\text { manufacturing }\end{array}$ & 1 & & & 1 & Improve \\
\hline Total $(\mathrm{h})$ & 116 & 46 & 16 & 54 & \\
\hline
\end{tabular}

\section{IMPROVE}

During this step, the team will implement all actions that were identified in the Analyse phase. For this given case, considering that the team is improving a strategic process of the company, they should ensure that this process is stable, predictable and meets customer requirements. Thanks to the Six Sigma's structured and step-by-step methodology, all of the mentioned process characteristics were already taken into consideration in both Measure and Analyse phases. At the end of the phase the team should also compare the results with the baselines given at the beginning of the project (especially with the set end measured KPIs).

To illustrate the process transformation, "To-be" process map (Fig. 10) was created where the obsolete steps are moved to the side of the flowchart and new connections or steps are created.

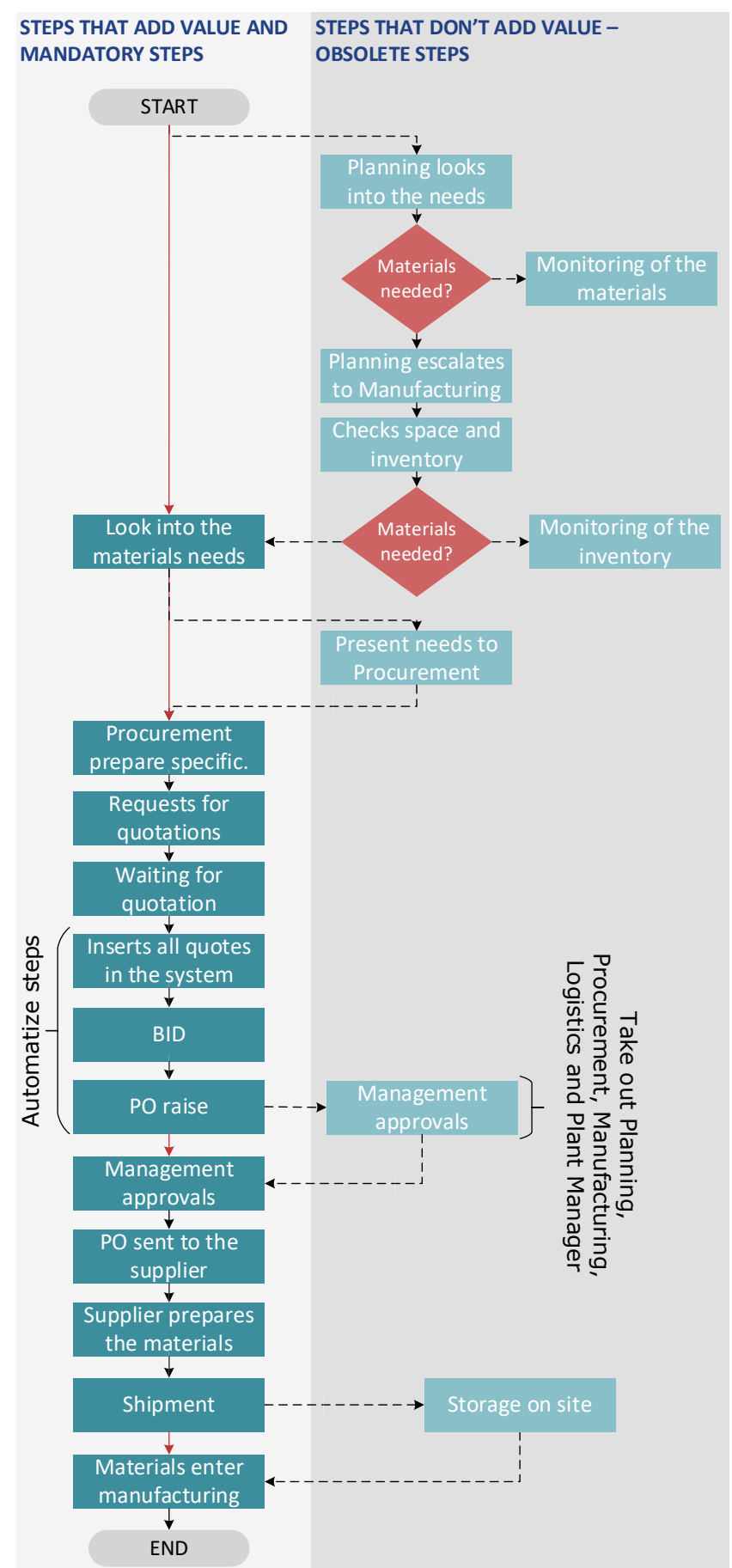

Figure 10 Map of the "to-be" process (light grey), the steps that are obsolete and will be eliminated (dark grey)

The final process, for comparation to the one on Fig. 6, could be seen on Fig. 11 with all removed and modified steps. 


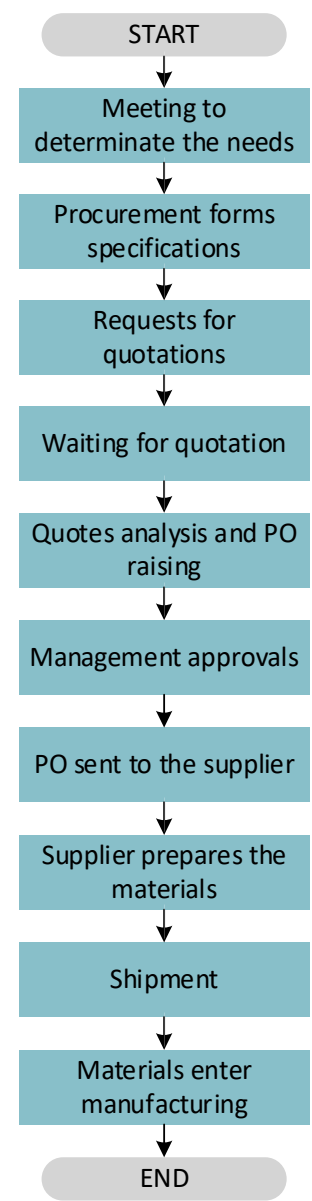

Figure 11 Map of the improved (final) process

\subsection{Compare Results to the Baseline}

The KPIs set and measured previously in the Measure phase of the project, are now re-measured. The goal is to quantify the success of the improvement after the implementation of the process.
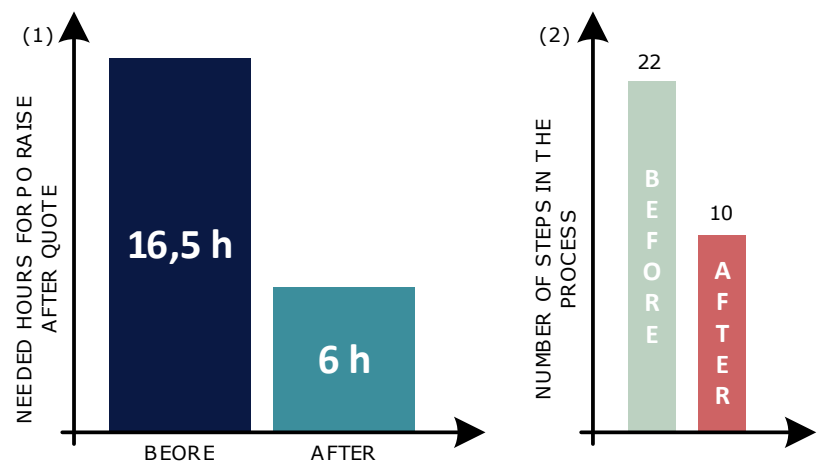

Figure 12 (1) Needed hours for raise a PO after the quote, (2) number of steps in the process before and after the improvement

The results of the re-measurement are given in Tab. 3, as well as on the chart in the following figures (Fig. 12 and Fig. 13).

The improvement of many KPIs is notable from Tab 3. For example, the hours needed for the suppliers to receive the
PO was decreased from 16,5 working hours to only 6 , which is mostly thanks to the reduced number of approvals by the different departments that was also reduced from 7 approvers to only 2 mandatory approvers.

Table 3 Comparation of the Key Performance Indicators measured in Measure phase and the current values of the same KPIs

\begin{tabular}{|l|c|c|c|}
\hline \multicolumn{1}{|c|}{ Indicator } & Unit & Before & After \\
\hline hours needed for vendors to receive PO & $\mathrm{h}$ & 16,5 & 6 \\
\hline mistakes in the Purchase Orders & $\#$ & 9 & 0 \\
\hline discounts from the suppliers monthly & $€$ & $4 \mathrm{k}$ & $12 \mathrm{k}$ \\
\hline delays of parts delivery due delay of the PO & $\mathrm{h}$ & 16 & 0 \\
\hline response time to vendor's questions & $\mathrm{h}$ & 8 & 1 \\
\hline number of steps in the procurement process & $\#$ & 22 & 10 \\
\hline number of approvers & $\#$ & $7-10$ & 2 \\
\hline length of the full process & $\mathrm{h}$ & 116 & 90 \\
\hline
\end{tabular}

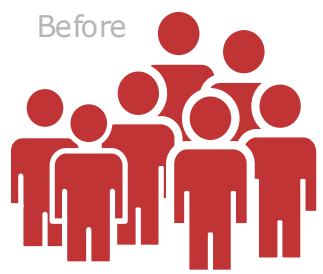

7 APPROVERS

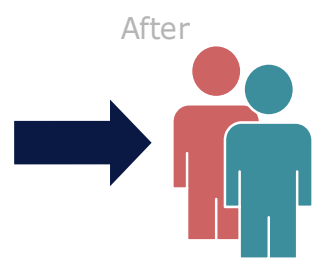

2 APPROVERS
Figure 13 Number of $\mathrm{PO}$ approvers before and after the improvement

\section{CONTROL AND MONITORING PLAN}

The modified process must be accepted by both internal stakeholders (company's departments) and external sides (vendors, suppliers and customers) in order to keep transparency and avoid miscommunications or generating waste (generating inventory, overproduction, transportation related waste of time, unnecessary steps etc.) in the future.

Internally, in the company, this will be performed in the following order:

- the procedure for procurement of raw goods will be completely revised in compliance with the internal Quality Management System,

- all relevant employees will be trained for this procedure,

- to avoid additional miscommunications, the change will also go through the internal Management of Change process where the entire management is responsible for understanding, approving, and sharing this change with their teams.

The external vendors should also be introduced to the process change due to compliance with the quality assurance standards up to a level of details which is defined in the nondisclosure agreement between the Company A and the possible suppliers of raw materials. The transparent approach regarding the process changes with the suppliers is mandatory if the Company A is looking forward to improving the communication and business with the suppliers.

The process will be monitored in the following steps that are considered to be the bottlenecks of the process:

- the Finances Department will be responsible to standardize a procedure/process for just-in-time 
approved funds for raw materials due to the importance of these materials for the overall production - Finances will frequently monitor the budget and make sure that funds are available in the right time,

- the Procurement manager will be responsible to perform a weekly audit of randomly selected vendors including the filled POs, the communication between the suppliers and the internal teams and the delivery of the materials,

- the Plant Manager will be responsible to audit the process - monthly,

- the attendance on the initial meeting for discussion regarding the needs will be mandatory and attendance tracker will show who, when and why was or wasn't attending the meeting,

- Planning department will be responsible to standardize a procedure for just-in-time purchasing and arrival of the raw materials - Planning will be responsible for implementation of this procedure as well as monitoring it,

- All managers approvals should be acquired within one hour after the PO release (this only applies to the raw materials POs), if not, needed approvers will be highlighted by the system and automatically followedup.

All these monitoring/controlling actions will be integrated in the new procedure for procurement of raw goods as well as the above-mentioned processes for JIT funds approvals and arrival of raw materials.

\section{CONCLUSIONS}

The purpose of this study was to improve the process for purchasing of raw materials in a real manufacturing company. The goal of the improvement was to enhance the concurrency of the process using the Lean Six Sigma framework for process improvement. The purchasing of the raw materials is one of the key aspects in the production planning and control process. This process used to be very repetitive, administrative and sequential which could be observed in the several flowcharts presented in the paper which was not sufficient for the company considering that this process is strategic and should be based on the optimized and Just-in-time needs for purchasing of the raw materials.

During this study, the team was using the DMAIC (define, measure, analyze, improve and control) framework to implement the improvement. The focus of the study is the Analyze and the Improve phases where the Value-added analysis is performed in the full scale. This analysis helped the team to reduce the number of steps in the process from 22 in the initial process to only 10 in the final process which is sufficient for this project to be a success. The analysis also has shown that many of the steps are repetitive and should be integrated and possibly automated. The number of meetings as well as number of PO approvers was set to bare minimum which saved at least 12 working hours. The full length of the process was brought from 166 working hours down to 92 hours for execution of the entire process including the needs identification, administrative procurement process and the delivery of the materials.

Due to the highly complicated process at the beginning, Six Sigma was the right choice for this improvement considering its facts-based and step-by-step approach which helped to clarify the process steps and all the involved sides.

\section{REFFERENCES}

[1] George, M. L. Rowlands, D., Pric, M., \& Maxey, J. (2005). The Lean Six Sigma Pocket Toolbook: A Quick Reference Guide to 100 Tools for Improving Quality and Speed, $1^{\text {st }}$ Edition.

[2] (2017). A guide to Project Management Body of Knowledge: PMBOOK Guide - Sixth Edition, Project Management Institute.

[3] Kochov, A. \& Argilovski, A. (2020). Case Study: Six Sigma Project for Reducing Manual Handling of Materials in Real Manufacturing Company. Tehnički glasnik, 14(4), 499-506. https://doi.org/10.31803/tg-20201002115534

[4] Prasad, B. (1996). Concurrent Engineering Fundamentals. Vol I: Integrated Product and Process Organization. https://doi.org/10.13140/RG.2.1.2613.0005

[5] See https://kanbanize.com/lean-management/improvement/5whys-analysis-tool

[6] Womack, J. P. \& Jones, D. T. (1996). Lean Thinking: Banish Waste and Create Wealth in Your Corporation. Journal of the Operational Research Society, 48(11). https://doi.org/10.1038/sj.jors.2600967

\section{Authors' contacts:}

Atanas Kochov, PhD

(Corresponding author)

Faculty of Mechanical Engineering - Skopje,

Karposh II bb, 1000 Skopje, Republic of North Macedonia

+389(0)71-299-299, atanas.kochov@mf.edu.mk

\section{Aleksandar Argilovski, MSc}

Faculty of Mechanical Engineering - Skopje, Karposh II bb, 1000 Skopje, Republic of North Macedonia +389(0)71-254-429, argilovski@hotmail.com 